\title{
Experimental Study on Wave Overtopping Force before a Vertical
}

\section{Breakwater}

\author{
Li han ${ }^{\mathrm{a}}$, Gui jinsong ${ }^{\mathrm{b}}$, Wang Dongxu ${ }^{\mathrm{c}}$ \\ Dalian Ocean University, Dalian 116024, China \\ aEmail: 996120169@qq.com; 'bmail: guijs@163.com; 'Email: 21140216@qq.com
}

Keywords: the vertical breakwater, overtopping, wave force.

Abstract. On the breast wall of a vertical breakwater, the measured wave forces have large deviations from the calculated values according to the current standard as a result of overtopping. In order to explore the reason of this deviation, the wave forces on vertical breast wall with overtopping have been measured through physical model test. By comparing and analyzing the measured values and normal calculated values, we discussed the influence of water depth and the amount of overtopping.

The distribution of wave pressure under different wave conditions is also tested by force sensors placed in the wave ward of the vertical breakwater. The test results show that the difference of two wave forces gets greater along with the increase of water depth and the height of overtopping. The main factors for the overtopping wave force are water depth and the amount of overtopping in contrast to period. Finally, we provide some suggestions about the optimization of design as a reference for the design of vertical breakwater according to the result of physical model test.

\section{Test overview}

This test is only for the wave force of the overtopping part of upright breakwater, by simulating the effect of waves on the vertical face of the trim breakwater, the wave force at the top of the vertical walls of the trim surface was measured. Investigating from the depth and overtopping, respectively, which is the tow aspects of research, by comparing the results of the test with that of the theoretical analysis, discuss the applicability of the recommended formula in the standard.

\section{Experiments}

\section{Equipment and Instruments}

The test was conducted in the sink port of Coastal Engineering Laboratory, Dalian Ocean University. Transparent glass was used to make the sink for easy observation during the test. The effective dimensions of the sink were $40 \mathrm{~m}$ in length, $0.7 \mathrm{~m}$ in width, $1.0 \mathrm{~m}$ in depth, which can accommodate a maximum depth of $0.7 \mathrm{~m}$. A servo motor irregular wave machine $(1.0 \mathrm{~m} \times 0.7 \mathrm{~m})$ was installed on one end of the tank, which can simulate a variety of regular and irregular waves with periods of between $0.5 \sim 5 \mathrm{~s}$. A vertical grid energy dissipation was installed on the rear of the sink to avoid the reflection waves.

DS30-type point pressure instrument is connected to a computer via a USB interface (2.0 model), and it can simultaneously control pressure data collection of up to 64 points, with a single-point sampling interval of 0.0015 seconds (approximately $666 \mathrm{~Hz}$ ). When the ambient temperature is between $0-30{ }^{\circ} \mathrm{C}$, temperature drift of the sensor is not greater than $\pm 0.5 \%$ of full scale. Frequency response of GYL-type point pressure sensor is not less than $1000 \mathrm{~Hz}$. 


\section{Model of the Text}

Model chosen scale of $1: 25$, the section of the breakwater includes caisson structure, wave-retaining wall, four-leg shoulder-protecting open squares and other bottom protection stones. In physical model tests, in addition to the geometric similarity between the entire cross-section and the prototype, the similarity of geometry, weight, center of gravity position and so on were all taken into consideration in all parts of the simulation above according to Wave model test procedures[1].

The trim surface parapet of the breakwater model has a top elevation of $0.64 \mathrm{~m}$, a parapet elevation of $0.17 \mathrm{~m}$. The parapet of the erect dike is wooden, with a height of $17 \mathrm{~cm}$ and a width of $48 \mathrm{~cm}$. A piece of iron was placed inside the parapet during the test to ensure the stability of the parapet.

\section{Wave Elements}

This test uses the depth: $11.0 \mathrm{~m}, 11.5 \mathrm{~m}, 12.0 \mathrm{~m}$; using four kinds of depth: $3.75 \mathrm{~m}, 4.25 \mathrm{~m}, 4.75 \mathrm{~m}$, $5.25 \mathrm{~m}$; use period $8 \mathrm{~s}$.

\section{Methods}

(1) Load cells were installed on the wave-retaining wall and the waveward side and the bottom surface of the caisson for measuring wave pressure distribution on each surface at different wave actions.

(2) The point pressure on each surface of the model were measured with data acquisition and processing system. All the test data was automatically collected and processed by a computer, with a wave power sampling interval of $0.02 \mathrm{~s}$. In each test, the data acquisition began after the waves had stabilized.

(3) Each experiment was repeated at least three times, and the mean value of each experiment was final test results.

\section{Results and Discussion}

In the case of overtopping, the calculation method of wave overtopping pressure is the same to the case of no overtopping, and we just need to remove wave pressure over the parapet according to Criterion of hydrology for port and channel[2]. But in the research, we found removing wave pressure over the parapet is not appropriate. Then the following experimental researches were carried out.

The effect forces and heights of the wave ward side of vertical breakwater parapet under three kinds of height were obtained by physical model test. For further investigate, we need these data for further analysis.

\section{The Variation of Total Horizontal Wave Force alone with Water Depth}

In the conditions of $\mathrm{H}=5.25 \mathrm{~m}, \mathrm{~T}=8 \mathrm{~s}$, the wave pressures of each measuring point are shown in Table1.

\begin{tabular}{|c|c|c|c|c|c|}
\hline \multirow{2}{*}{ depth } & $\begin{array}{c}\text { Measuring } \\
\text { point }\end{array}$ & distance $(\mathrm{m})$ & $\begin{array}{l}\text { measured } \\
\text { values }(\mathrm{kpa})\end{array}$ & $\begin{array}{c}\text { specification } \\
(\mathrm{kpa})\end{array}$ & Spe/Mea \\
\hline \multirow{5}{*}{$\mathrm{d}=12$} & $1 \#$ & 0.25 & 17.54 & 22.63 & 1.29 \\
\cline { 2 - 6 } & $2 \#$ & 1.25 & 23.56 & 30.62 & 1.30 \\
\cline { 2 - 6 } & $3 \#$ & 2.25 & 28.45 & 39.39 & 1.38 \\
\cline { 2 - 6 } & $4 \#$ & 3.5 & 39.18 & 50.36 & 1.29 \\
\cline { 2 - 6 } & $5 \#$ & 5 & 41.26 & 55.54 & 1.35 \\
\hline \multirow{3}{*}{$\mathrm{d}=11.5$} & $1 \#$ & 0.25 & 15.57 & 18.84 & 1.21 \\
\cline { 2 - 6 } & $2 \#$ & 1.25 & 20.46 & 24.24 & 1.18 \\
\hline
\end{tabular}




\begin{tabular}{|c|c|c|c|c|c|}
\hline \multirow{5}{*}{} & $3 \#$ & 2.25 & 23.39 & 27.30 & 1.17 \\
\cline { 2 - 6 } & $4 \#$ & 3.5 & 32.02 & 43.76 & 1.37 \\
\cline { 2 - 6 } & $5 \#$ & 5 & 43.56 & 55.70 & 1.28 \\
\hline \multirow{4}{*}{$\mathrm{d}=11$} & $1 \#$ & 0.25 & 13.97 & 15.09 & 1.08 \\
\cline { 2 - 6 } & $2 \#$ & 1.25 & 17.53 & 19.43 & 1.11 \\
\cline { 2 - 6 } & $3 \#$ & 2.25 & 20.82 & 28.01 & 1.35 \\
\cline { 2 - 6 } & $4 \#$ & 3.5 & 29.17 & 38.74 & 1.33 \\
\cline { 2 - 6 } & $5 \#$ & 5 & 42.65 & 55.87 & 1.31 \\
\hline
\end{tabular}

Table1 Horizontal wave pressure of breast wall at different water depths

As can be seen in Table2, the wave pressure from the sensor 1\# at the parapet top decreases as the water depth increases. There is nearly $15 \%$ to $35 \%$ gap compared with the specification value of wave pressure. And the disparity increases as the water depth increases. The disparities between the measured value and specification of other working conditions are consistent with the above-mentioned conditions. 。

\section{The Influence of Wave Height on Wave Pressure}

In conditions of $\mathrm{d}=12 \mathrm{~m}, \mathrm{~T}=8 \mathrm{~s}$ :

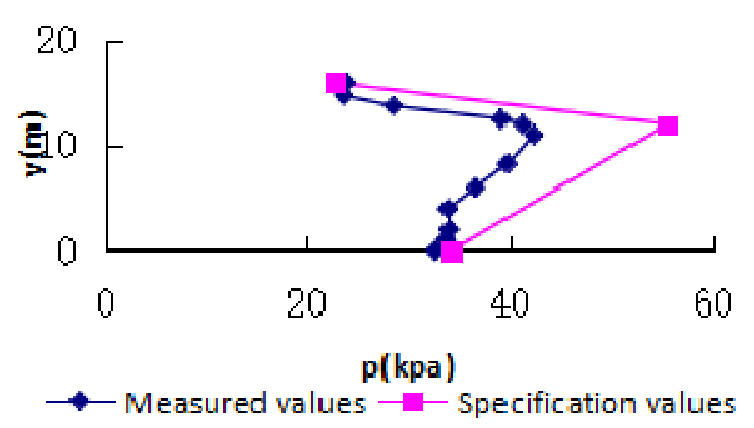

Fig. $1 \mathrm{H}=5.25 \mathrm{~m}$, the pressure on parapet

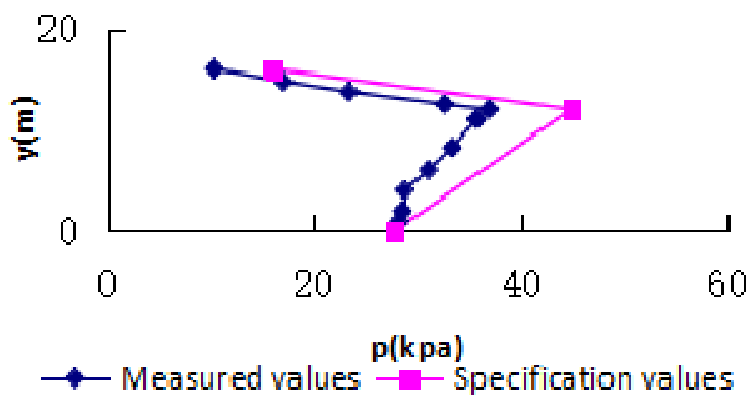

Fig. $3 \mathrm{H}=4.25 \mathrm{~m}$, the pressure on parapet

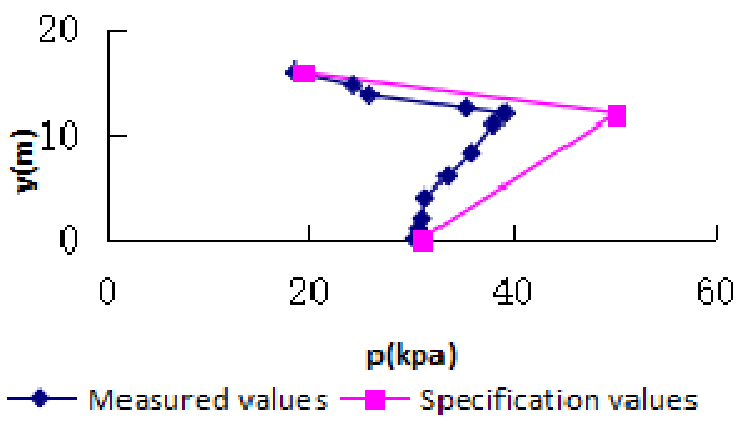

Fig. $2 \mathrm{H}=4.75 \mathrm{~m}$, the pressure on parapet

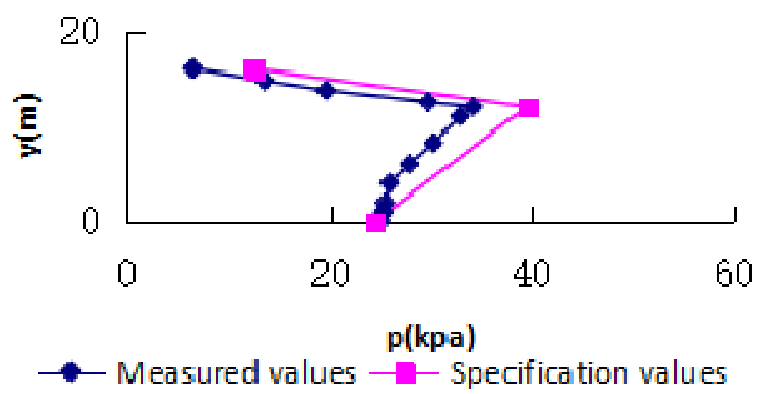

Fig. $4 \mathrm{H}=3.75 \mathrm{~m}$, the pressure on parapet

In conditions of $\mathrm{d}=11 \mathrm{~m}, \mathrm{~T}=8 \mathrm{~s}$ : 


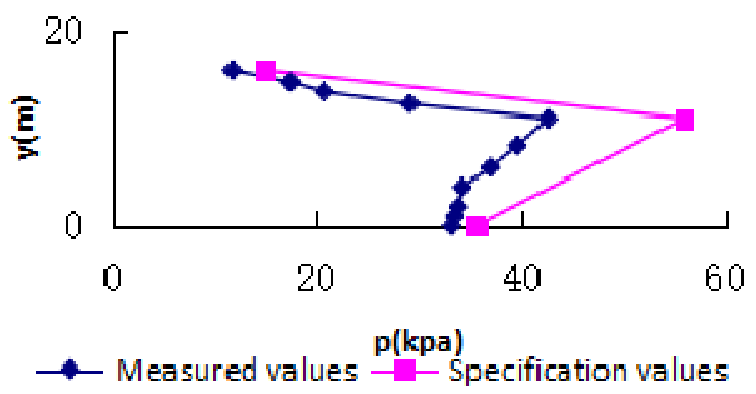

Fig. $5 \mathrm{H}=5.25 \mathrm{~m}$, the pressure on parapet

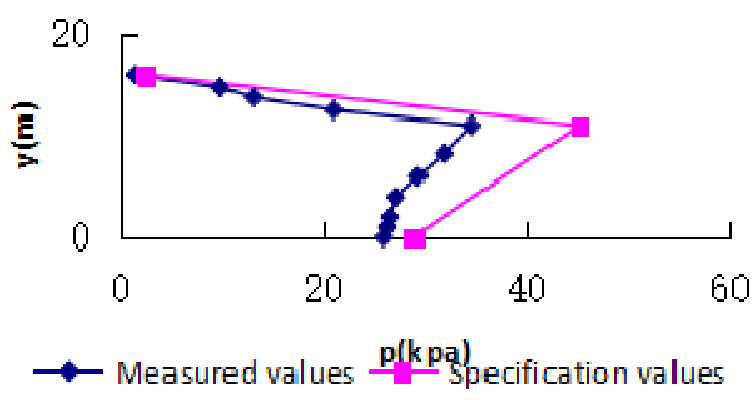

Fig.7 $\mathrm{H}=4.25 \mathrm{~m}$, the pressure on parapet

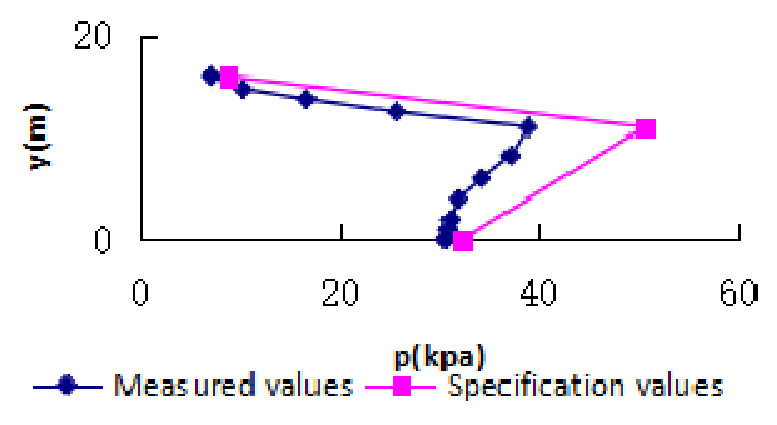

Fig. $6 \mathrm{H}=4.75 \mathrm{~m}$, the pressure on parapet

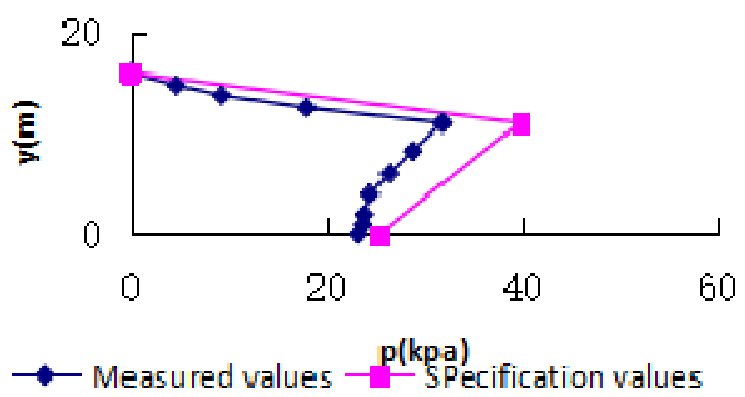

Fig. $8 \mathrm{H}=3.75 \mathrm{~m}$, the pressure on parapet

It can be seen from the working condition 1, with the decrease of the wave height, the actual pressure wave amplitude decrease is larger than specification pressure wave. The working condition 2 shows that when the wave overtopping is little or inexistence, the disparity between the actual value and the specification value is getting smaller and smaller. When the overtopping is little, the actual value and the specification value are more consistent. That's because the overtopping is so little that most of the wave is blocked by vertical walls. This proves that the actual value and the specification value are consistent when overtopping is inexistence and this two values are not consistent in the overtopping conditions, thus further improvements are needed.

\section{Conclusions}

(1) The standardized value of each measurement point is greater than the measured value under all the 16 operating conditions in this paper. Thus the measured wave pressure curves are all surrounded by the standard wave pressure curves. In this case, the safety regulations for engineering calculations are ensured.

(2) Because of the overtopping, the gap between measured wave pressure values and normative wave pressure values becomes greater with the increase of wave overtopping. The measured wave pressure values are $5 \%$ to $35 \%$ less than the normative values.

(3) According to the distribution of wave pressure at wave ward side on the vertical breast wall, the following rules can be obtained: When calculating the wave force on a parapet of the vertical breakwater, the author discovered the wave pressure exhibits trapezium distribution under a great overtopping conditions and the measured wave force is $20 \%$ less than the normative values. The calculated value based on this paper is greater than the measured value, but ensuring the safety regulations. 


\section{References}

[1]Wave model test procedures (JTJ/T234-2001)

[2]Criterion of hydrology for port and channel (JTJ 145-2-2013) 